\title{
Development and validation of the Good Lives Questionnaire
}

Craig A. Harper ${ }^{1 *}$, Rebecca Lievesley ${ }^{1}$, Nicholas Blagden ${ }^{1}$, Geraldine Akerman ${ }^{2,3}$, Belinda Winder ${ }^{1}$, \& Eric Baumgartner ${ }^{4}$

${ }^{1}$ Department of Psychology, Nottingham Trent University (UK)

${ }^{2}$ HMP Grendon (UK)

${ }^{3}$ Cardiff Metropolitan University (UK)

${ }^{4}$ School of Education and Social Sciences, University of the West of Scotland (UK)

*Corresponding author

Dr. Craig Harper

Department of Psychology

Nottingham Trent University, 50 Shakespeare Street, Nottingham, NG1 4FQ, UK

Email: craigaharper19@gmail.com Tel: +44 (0)1158484718 Twitter: @CraigHarper19

\section{Funding Note}

The research described in this article was made possible thanks to a grant provided by the Safety and Security of Citizens and Society Research Theme at Nottingham Trent University. The funders played no role in the planning or conduct of this research, or in the decision to publish. 


\begin{abstract}
The Good Lives Model (GLM) is a framework of rehabilitation when working with individuals who have committed criminal offenses. However, its core assumptions (i.e., that the 'good life' is comprised of various universal primary human goods) have not been tested, and there is no standardized measure of these concepts. We used a large community sample $(N=1,309)$ to develop a measure of primary human goods. Our 100-item draft Good Lives Questionnaire (GLQ) was reduced to 35 items via exploratory principal components analysis $(n=900)$, with its five-factor structure supported by confirmatory factor analysis $(n=409)$. This structure runs counter to the existing scholarship related to the GLM, which proposes eleven primary human goods. We found each of our factors - 'Inner Peace', 'Energy and Agency', 'Social Connectedness', 'Varied Leisure Activities', and 'Spirituality' - to be differentially associated with measures of self-reported aggression, criminality, and delinquency, supporting its validity as a measure of crime- and delinquency-related constructs. They were also associated with measures of psychological wellbeing, personal agency, social connectedness, and personality. We discuss the future validation of the GLQ, as well as its potential utility in clinical and forensic settings.
\end{abstract}

Key words: Good Lives Model, primary human goods, scale development, offender rehabilitation, forensic psychology 


\section{Development and validation of the Good Lives Questionnaire}

\section{Introduction}

Identifying common deficits in individuals who have offended has a long history, with Lombroso, founder of the positivist school of criminology in Italy (Musumeci, 2013), being one of the earliest proponents. Lombroso argued these deficits were biologically determined, only recognizing the role of environmental factors in his later work (Ferrati, 1996). The identification of deficits, and their role in predicting reoffending was a significant focus of risk assessment in the 50 years up to the 1990s (see Andrews, Bonta \& Wormith, 2006). At that time, the focus changed to utilizing measures of deficits (risk factors) to reduce and manage the risk of individuals who might reoffend (Andrews et al., 2006). This reorientation of focus was partly because of growing societal concern because of the risk of reoffending by individuals who had previously committed sexual or violent crimes (Prins, 1996). This concern was reflected in the national guidance to probation officers that was issued during this period for dealing with so-called 'dangerous offenders' (Home Office, 1995). In line with this deficits-based approach, Andrews and Bonta (1994) set out principles for the risk management of people who had offended in their risk-need-responsivity model of rehabilitation. This framework argues that those posing the highest re-offense risk should receive the greatest treatment input (the risk principle), that forensic interventions should target specific criminogenic needs that are directly linked to offending (the need principle), and that individuals' abilities and mindsets should be taken into account when choosing the delivery modality of interventions (the responsivity principle).

Since the turn of the century, however, there has been a noticeable shift in the philosophical approach taken to the rehabilitation of individuals who have offended, with positive psychological approaches coming to the fore (Looman \& Albracen, 2013; 
Woldgabreal, Day, \& Ward, 2014; 2016). The notion that positive experiences are an important component of satisfaction and achievement is embedded within Maslow's (1948) seminal model of the hierarchy of human needs. This includes both the removal of negatives (e.g., hunger, fear) and the promotion of positives (e.g., community, self-actualization). Thus, it is perhaps not surprising that positive psychological models have also emerged as a means of reducing reoffending.

\section{The Good Lives Model}

The Good Lives Model (GLM; Ward \& Stewart, 2003) represents one such strengthsbased positive psychological approach to the treatment and rehabilitation of individuals with criminal convictions. The central tenet of the GLM is that people are striving to achieve a set of 'primary human goods' (Ward \& Gannon, 2006; Ward \& Stewart, 2003), which are defined as "states of affairs, state of minds, personal characteristics, activities, or experiences that are sought for their own sake and are likely to increase psychological well-being if achieved" (Laws \& Ward, 2011, p. 184). This is in contrast to historical approaches to criminal justice that have focused on deficits-based approaches, as previously outlined (for comprehensive reviews, see also Baumgartner, 2014; Ward \& Maruna, 2007). The premise of the GLM is that individuals will move onto trajectories of (re)offending behavior if they either (a) fail to achieve primary human goods, or (b) utilize antisocial or delinquent methods to achieve them. To date, eleven primary human goods have been delineated (Purvis, Ward, \& Willis, 2011):

1. Life (i.e., living and functioning in a physically healthy way)

2. Knowledge (i.e., feeling informed about the world and things important to the individual)

3. Excellence in play (i.e., having a range of hobbies and interests) 
4. Excellence in work (i.e., having something that one is considered an 'expert' in)

5. Excellence in agency (i.e., having autonomy in decision-making)

6. Inner peace (i.e., emotional health and freedom from stress)

7. Friendship (i.e., having relationships in intimate, romantic, and family domains)

8. Community (i.e., having a connection to a broader social group or community)

9. Spirituality (i.e., finding meaning and / or purpose in life)

10. Happiness / Pleasure (i.e., feelings positive in the here-and-now)

11. Creativity (i.e., the ability to express oneself through a range of different methods).

These primary human goods have emerged from the extant literature related to subjective wellbeing and quality of life. It is important to note that this eleven-factor structure has not always been theoretically supported, with earlier reviews of the GLM suggesting the existence of six (Marshall, Marshall, Serran, \& O’Brien, 2011), nine (Ward \& Marshall, 2004), and ten (Ward \& Gannon, 2006) clusters of primary human goods. This inconsistent conceptualization leads us to argue that a systemic empirical examination of how these primary human goods cluster when measured is an important endeavor.

The GLM suggests that offending stems from individuals utilizing maladaptive strategies, perhaps due to the lack of appropriate internal and external resources, to obtain what they value in an antisocial manner (Ward \& Stewart, 2003). Thus, individuals who offend are not seeking the 'wrong' primary human goods, for these goods are said to be ubiquitous across human societies (Ward \& Stewart, 2003). Instead, it is the way in which primary human goods are sought that sets people at odds with the rest of society. There are four ways in which criminogenic needs are purported to interfere with the acquisition of primary human goods by an individual: (1) the means by which an individual seeks to secure primary goods is inappropriate; (2) an overly restricted scope or range of primary goods are 
sought by an individual (meaning that the individual is left with an imbalance and lack in their life); (3) there is conflict in the pursuit of two primary goods (such that the strategy for acquiring one type of primary good impairs another primary good); (4) a lack of personal capabilities (e.g., knowledge, ability) to secure primary goods (Ward \& Stewart, 2003; Ward, Mann, \& Gannon, 2007).

Applying the GLM to the treatment and rehabilitative context, this approach augments the risk-based model by placing equal emphasis on giving "offenders the capabilities to secure important personal and social experiences ('goods') in acceptable ways"' (Mann, 2004, p. 142). This move begins to consider the importance of desistance-related and protective factors held by individuals who offend (Harkins, Flak, Beech, \& Woodhams, 2012; de Vries Robbé, Mann, Maruna, \& Thornton, 2015). Protective factors are social, interpersonal, and environmental factors, as well as psychological and behavioral features that are empirically linked to offending behavior (de Vries Robbé et al., 2015). The treatment of specific criminogenic needs are thus addressed alongside the rehearsal of generally prosocial skills, such as improving individuals' capacities for forming and maintaining close relationships, finding healthy expressions of energy in the form of hobbies, and gaining control over emotional regulation (Akerman, 2019). Within treatment programs, the four problematic ways to achieve primary goods (see above) are discussed and reflected upon by both service users and clinicians (Akerman, 2008; Brookes, 2010) to facilitate the development of a prosocial identity among service users, which according to Ward and Maruna (2007) improves the likelihood of long-term criminal desistance. Fundamental to this implementation is the active process of goal setting, which helps service users to develop a sense of agency (McMurran \& Ward, 2004). In setting goals, clinicians can work with service users to develop Good Lives Plans (GLPs) that incorporate evidence-based techniques (e.g., 
mindfulness for psychological wellbeing and emotion regulation, education for employment prospects) to help service users achieve their life goals (Ward \& Fortune, 2013).

\section{Operationalization and measurement of the GLM in practice}

The GLM has been criticized for a lack of a rigorous quantitative evidence-base, for incoherent measurement, and for not adding anything substantive to reducing recidivism over-and-above what is offered by other models of rehabilitation (Andrews, Bonta, \& Wormith, 2011; Looman \& Albracen, 2013; Netto, Carter, \& Bonnell, 2014). These issues have led to the enactment of inconsistencies in assessing the needs of individuals who have offended, as professional discretion becomes embedded in forensic practice (Phoenix, 2009).

Although the GLM lacks empirical support in relation to reducing criminal recidivism (Netto et al., 2014), there are strong philosophical reasons for its implementation, and its theoretical position has been important for developing strengths-based forensic practice (Willis \& Ward, 2013). However, the GLM has been inconsistently operationalized in treatment programs, with some of the features of many GLPs (e.g., the use of approach vs. avoidance related goals) not being unique to a GLM approach (Willis, Ward, \& Levenson, 2014). Ware and Bright (2008) adopted GLM principles in their prison-based treatment program for individuals with sexual convictions and focused on "structuring treatment to reflect the good lives rehabilitation model, whereby it is strength based and concerned with promoting offenders' goals alongside the management of their recidivism risk" (p. 347). While they did not evaluate the model in terms of its effects on recidivism outcomes, this process of service evolution involved reducing service user confrontation, working empathetically with service users, and working collaboratively toward share treatment goals. Further, Marshall et al. (2011) described a strength-based approach to the treatment of individuals with sexual convictions, which incorporates many GLM-related concepts. Their 
intervention condenses the eleven primary goods into six areas: health, mastery, autonomy, relatedness, inner peace, knowledge and creativity. In their evaluation, they found a $3.2 \%$ sexual recidivism rate over 5.4 years and a $5.6 \%$ rate at 8.4 years. This compares favorably to standard risk-reduction-based treatment outcomes for this population reported since this intervention was administered (rates of $10.1 \%$ and $14.2 \%$ at these approximate time points; Hanson, Harris, Helmus, \& Thornton, 2014). However, the Marshall et al. (2011) good lives intervention did not follow the traditional GLM framework, by collapsing the eleven primary human goods into six broader conceptual areas. This suggests some potential for redundancy in the standard conceptualization of the GLM, as advanced by Ward and colleagues over a number of years.

Although the framing of the GLM, and its implementation, has been focused in the areas of criminal justice and the rehabilitation of individuals with (typically sexual) offenses, the pursuit of primary human goods is said to be universal (e.g., Ward \& Birgden, 2007). For this reason, it may also be important to examine the composition and achievement of primary human goods in groups that, although not offending, demonstrate troubling behaviors (e.g., deviant sexual interests, or excessive levels of aggression). In doing so, knowing the clusters of primary human goods that are associated with potentially problematic or sub-criminal behaviors may allow for the empirically based development of primary and secondary prevention programs to mitigate such risks. To our knowledge, no published research has systematically cluster primary human goods in a data-driven manner, and link these to aggressive behavior in non-offending samples.

Not only have the GLM principles been inconsistently operationalized, they have also been inconsistently and subjectively measured. In a study evaluating a GLM based module in a treatment intervention, Harkins, Flak, Beech, and Woodhams (2012) used a standard psychometric test battery that is routinely collected for evaluating the effectiveness of 
interventions for individuals with sexual convictions (e.g., self-esteem, loneliness, interpersonal reactivity, locus of control), in addition to an interview focused on participants perceptions of the module. Others have suggested the use of GLM-informed assessment which involves an assessment of a client's primary goods and an evaluation of how they have gone about attaining these goods, and identifying problems or flaws in a client's past and current GLP (Willis, Yates, Gannon, \& Ward, 2012; Yates \& Prescott, 2011). There are various forms of this assessment including a structured clinical interview for identifying how heavily weighted (i.e., important) each primary human good is for individual service users (see Yates \& Prescott, 2012; Willis et al., 2012). This subjectivity of conceptualization and inconsistency of implementation hinders the empirical basis of the GLM and the generalizability of research evaluations, as, at present, most findings cannot extend beyond their local intervention context. This is supported by Netto et al.'s (2014) systematic review of GLM-informed forensic interventions, wherein it was concluded that "although practitioners may value the potential of good lives interventions to improve engagement, motivation, and lower attrition, the dearth of high quality evidence prohibits drawing definitive conclusions about its effectiveness in these domains" (p. 415-416).

When looking to measure the role of primary human goods in offending populations, Yates, Kingston, and Ward (2009) developed a structured interview schedule for researchers and clinicians to use with forensic clients. After presenting a definition of each primary human good, service users are asked to consider and elaborate on the various strategies that they have previously used when trying to achieve these goods, which strategies worked well or badly, how others had been hurt in the pursuit of each good, and how these may be related to their offending behavior. Service users are also asked to think about the relative importance of each primary human good to them personally, whether the extent of their striving for particular goods is adaptive or maladaptive, and how their life would look should 
they achieve (or fail to achieve) each primary human good. In this schedule, standard GLM definitions of the primary human goods (such as those given above) are provided, with no systematic test of the component structure of the GLM being presented.

At present, however, the only work that has sought to standardize the measurement of GLM-related concepts in a quantitative manner was published by Loney and Harkins (2018). Here, the authors provided community members with a description of each of the 11 primary human goods outlined by Purvis et al. (2011), and a list of potential strategies for achieving these. These strategies included a range of adaptive and maladaptive options, with participants being required to identify which strategies they had previously used, in addition to whether these strategies had been effective. Further, participants rated each primary human good in terms of its subjective importance to them. The resultant scale was called the Measure of Life Priorities (MLP). Consistent with Loney and Harkins' (2018) hypotheses, participants identified each primary human good as being important to them, and maladaptive strategies for achieving them (or not having a sufficient number of effective strategies) were associated with an increased propensity for antisocial behavior. However, the MLP was not developed in a systematic way. That is, no formal scale development procedures (e.g., item construction or reduction, or an independent confirmatory analyses of the dimensional structure of the MLP) were reported by Loney and Harkins (2018), meaning that this too may suffer from the same limitations as those other studies mentioned previously. As such, there is still a gap within the literature for the systematic development of a measure related to the primary human goods, as set out within the GLM.

\section{The present research}

As outlined above there are number of subjectivities in the conceptualization and measurement of primary human goods, and a lack of systematic examinations of whether any 
of the hypothesized groupings of these goods are supported by systematic empirical examination, or whether these theoretically attractive delineations present differently when items related to them are factor-analyzed. Examining the eleven goods proposed by Purvis et al. (2011), several of these may cluster into a smaller number of groupings. For example, primary goods related to life, inner peace, spirituality, and happiness could be clustered into a broader 'health and wellbeing' grouping, goods relating to play, relatedness, and community into a 'connectedness' grouping, and goods related to work, knowledge, agency, and creativity into an 'agency / self-control' grouping.

The aim of this paper is to present the development and initial validation efforts for a measure of primary human goods: the Good Lives Questionnaire (GLQ). In doing so, we sought to develop a first draft of the GLQ, reduce this to a manageable length for use in social research and applied psychological settings using factor analysis techniques, confirm its factor structure using an independent sample of participants, and explore its ability to predict aggression, criminal behavior, and non-criminal delinquency in a non-offending sample. This exercise is both useful and necessary, as a lack of standardized measure of primary human goods may be one of the key reasons behind why there is a scarcity of empirical work undertaken into the effectiveness of the GLM (Looman \& Albracen, 2013; Netto et al., 2014). Our use of a non-offending sample reflects the theoretical work on the universal nature of primary human goods. That is, our aim is to understand the structure of primary human goods in a normative sample, to validate this structure by looking at relationships to relevant psychological constructs, and then use this as a foundation for applied research with the GLQ. 


\section{Methods}

\section{Participants}

Using established guidelines on factor analysis sample size, we required five-to-ten observations per scale item in the exploratory analysis (Costello \& Osborne, 2005; Mundfrom, Shaw, \& Ke, 2005), and more than 300 participants in our confirmatory analyses (Myers, Ahn, \& Jin, 2011). Owing to the length of the first draft of GLQ, we thus sought to recruit a sample at the upper end of this required ratio. As such, approximately 1300 participants (900 for exploratory factor analysis of the GLQ, and 400 for a confirmatory factor analysis) were sought for the project.

Using crowdsourcing recruitment methods using Prolific, we recruited a total of 1,331 British participants for an online survey. We retained all participants who completed the draft GLQ, irrespective of whether they completed all other measures in our survey. Noncompletion of other measures was not considered withdrawal from the study. Instead, participants were asked to follow a specific procedure (contacting the first author anonymously via a letter, in line with suggestions from the reviewing ethics committee) to indicate their non-consent for data usage. One participant explicitly refused consent and was therefore unable to respond to any questions in the survey. In addition, 21 participants did not complete the draft GLQ. This led to a final sample of 1,309 participants $\left(51 \%\right.$ male; $M_{\text {age }}=$ 38.12 years, $S D=13.84)$.

Within our full data file, we ordered participants arbitrarily using their ID number on the Prolific platform. This procedure was performed to pseudo-randomize the order of participants. The first 900 participants were assigned in the data file to the exploratory analysis sample (an observation-to-item ratio of 9:1), and the remaining 409 participants to the confirmatory analysis sample. Specific demographic characteristics of each sample are provided in Table 1. 
Table 1. Demographic characteristics of 'exploratory' and 'confirmatory' analysis samples

\begin{tabular}{lcc}
\hline & \multicolumn{2}{c}{ Sample } \\
\cline { 2 - 3 } Variable & $\begin{array}{c}\text { Exploratory } \\
(n=900)\end{array}$ & $\begin{array}{c}\text { Confirmatory } \\
(n=409)\end{array}$ \\
\hline Sex $(\%$ male) & $41.7 \%$ & $57.2 \%$ \\
Age (years) & $39.86(12.72)$ & $34.28(15.35)$ \\
In a relationship (\% yes) & $70.4 \%$ & $73.1 \%$ \\
Education level (scaled) & $3.58(1.08)$ & $3.50(0.98)$ \\
Social class (scaled) & $2.63(0.74)$ & $2.66(0.76)$ \\
Convictions (\% yes) & $3.8 \%$ & $3.7 \%$ \\
\hline
\end{tabular}

\section{Measures}

Demographics. Participants were asked to respond to a number of demographic questions. Specifically, we asked for information about sex (male / female), age, whether they were in a committed relationship (yes / no), their highest obtained qualification (none / GCSEs / A-levels / undergraduate degree / postgraduate degree / doctorate; scored as a 1-6 scale), self-identified social class (poor / working class / lower middle class / upper middle class / upper class; scored as a 1-5 scale), and whether they had any criminal convictions (yes / no, and if yes, how many?).

Good Lives Questionnaire. Taking Purvis et al.’s (2011) eleven primary human goods as a guide, we began by developing a number of potential scale items for each of these domains as a first draft of the Good Lives Questionnaire (GLQ). We wrote eight items per primary good, anticipating some degree of scale reduction following subsequent factor analysis. A list of the final items is presented in Table 2, while a full list of all 100 items used in the draft GLQ is available for download at https://osf.io/rnxgu/. In addition, we added Snyder et al.'s (1991) hope scale to this draft GLQ following claims that having hope about one's future prospects could be considered within the positive psychology or GLM 
framework (Woldgabreal et al., 2016). That is, individuals who have a long, persistent history of offending behavior are characterized by a lack of hope and reduced feelings of personal agency (Maruna, 2001; Zamble \& Quinsey, 1997). Specifically, desistance researchers have found that a lack of hope is related to the notion of individuals feeling that they are 'doomed to deviance', whereas hope for a positive future has been found to help desisting men to maintain an optimistic sense of control over their future (LeBel et al, 2008; Maruna, 2001).

In order to reduce bias, we presented all of these items in a random order for each participant, meaning that any observed factors underpinning the measure were due to them clustering around a homogeneous theme, rather than being reflective of the order in which they were responded to. Participants indicated their level of agreement using a six-point Likert scale, anchored from 'strongly disagree' to 'strongly agree'.

Aggression Questionnaire. The Buss and Perry (1992) Aggression Questionnaire was used to measure physical aggression (nine items; e.g. "Once in a while I can't control the urge to strike another person"; $\alpha=.82$ ), verbal aggression (five items; e.g., "I often find myself disagreeing with people"; $\alpha=.81$ ), anger (seven items; e.g., "I have trouble controlling my temper"; $\alpha=.84$ ), and interpersonal hostility (eight items; e.g., "I am suspicious of overly friendly strangers"; $\alpha=.87$ ). Each item was rated using a five-point scale anchored from 'extremely uncharacteristic of me' to 'extremely characteristic of me'. Average scores were computed for each aggression domain, with high scores indicating more aggression.

Although we explicitly made use of a non-offending sample in this project, those demonstrating high scores on the Buss-Perry Aggression Questionnaire have been shown to demonstrate forensic-related behaviors, such as emotional reactivity to perceived provocation, poor situational problem-solving, interpersonal aggression, impulsivity, and 
attempts at relational dominance (Archer \& Webb, 2006; de Schutter, Kramer, Franken, Lodewijkx, \& Kleinepier, 2016; Tremblay \& Ewart, 2005). According to Chung et al. (2019), a total score of 69 on the Buss-Perry Aggression Questionnaire (equivalent to an average item score of 2.38 out of 5) may indicate a problematic level of aggression. In our sample, 714 participants met this threshold $(54.5 \%)$. As such, although we purposively recruited a community sample, they may share some of the characteristics of a forensic sample (though to a lesser degree). This is important as not only can we test the psychometric properties of our developed GLQ, but we are also able to make realistic hypotheses and inferences about how it may be applicable in the forensic domain.

Crime and Delinquency Measure. We adapted scales used by Chen, Voisin, and Jacobson (2016) and Elliot, Huizinga, and Ageton (1985) to create measures of criminal behavior (nine items; e.g., "Stolen money or taken something that did not belong to you") and non-criminal delinquency (nine items; e.g., "Cheated at work to get ahead of colleagues"). Participants indicated how often they had engaged in each behavior in the past 12 months using the responses 'never', 'once', '2-5 times', '5-10 times', or 'more than 10 times', with responses being scored as 1-5. An average score was computed for each subscale.

Psychological Wellbeing Scale. A unidimensional measure of psychological wellbeing (Villar, Triadó, Celdrán, \& Solé, 2010) was used to measure participants' abilities to manage their personal lives and plan effectively for the future. Each of the 22 items (e.g., "It is difficult to arrange my life in a satisfactory way"; reverse-scored) was rated using a four-point scale anchored from 'strongly disagree' to 'strongly agree'. The scoring range was thus 22-88, with high scores indicating better psychological adjustment and wellbeing. This measure demonstrated excellent internal consistency $(\alpha=.90)$. 
Sense of Community Connectedness Scale. The Sense of Community Connectedness Scale (Flanagan, Cumsille, Gill, \& Gallay, 2007) was used to measure the extent to which participants felt connected to their local communities. A total of 11 items (e.g., "In general, people pull together to help each other") were rated using a five-point scale anchored from 'strongly disagree' to 'strongly agree'. Scores ranged from 11-55, with high scores indicating higher levels of perceived social connection. This measure demonstrated very good levels of internal consistency $(\alpha=.88)$.

Personal Agency Scale. The seven item Personal Agency Scale (Helgeson \& Palladino, 2012) was used to measure the extent to which participants felt as though they had some degree of control and independence in their lives. Each item (e.g., "I would rather do things for myself than ask others for help") was rated using a five-point scale anchored from 'strongly disagree' to 'strongly agree', with a potential scoring range of 7-35. Higher scores indicated more perceived personal agency. The measure demonstrated acceptable levels of internal consistency $(\alpha=.71)$.

Ten-Item Personality Inventory. The Ten-Item Personality Inventory (Gosling et al., 2003) was used to explore the extent to which participants viewed themselves as extraverted (e.g., "extraverted, enthusiastic"; $\alpha=.73$ ), agreeable (e.g., "sympathetic, warm"; $\alpha=.38$ ), conscientious (e.g., "dependable, self-disciplined"; $\alpha=.56$ ), emotionally stable (e.g., "calm, emotionally stable"; $\alpha=.74$ ), and open (e.g., "open to new experiences, complex"; $\alpha=.48$ ). Each trait was rated using two pairs of attributes (one positively-framed, one negativelyframed) using a seven-point scale anchored from 'disagree strongly' to 'agree strongly'. Responses were averaged for each trait with high scores indicating more identification with 
that trait. Due to the low number of items per trait, internal consistency coefficients were variable.

\section{Procedure}

Participants were invited to complete an online survey through the Prolific crowdsourcing system. Only registered users who met our inclusion criteria (i.e., a minimum age of 18 years, and British nationality and residence) were able to access the advertisement. We subsequently set up one task for males and another task for females to ensure a sexbalanced final sample. After reading the study advertisement, participants who were interested in completing the survey clicked on the survey web-link where they were able to access a more detailed informed consent screen

After providing their consent, participants first provided their demographic information, before completing the draft GLQ. The order of the items in the GLQ was randomized for each participant to reduce order effects using the choice randomization tool built into the Qualtrics survey software. After this, participants completed the Aggression Questionnaire and the crime and delinquency measure in an order that was counterbalanced betweenparticipants, to test the GLQ's predictive validity. Subsequently, participants then completed the Psychological Wellbeing Scale, Sense of Community Connectedness Scale, Personal Agency Scale, and the Ten-Item Personality Inventory in an order that was counterbalanced between participants. These latter scales were included in order for us the later examine the GLQ's convergent and divergent validity. All counterbalancing was performed using randomizer tools within the Qualtrics survey flow.

All participants received a comprehensive debriefing at the end of the survey, which outlined the aims of the study and details about the types of measures contained within the survey. Upon clicking a button to confirm their responses, participants were automatically 
redirected to the Prolific platform, where their participation was logged. Open materials in the form of a Qualtrics .qsf survey file can be downloaded from [OSF link to go live upon acceptance to ensure anonymous peer-review]. All participants received $£ 1.40$ (approx. $\$ 1.75)$ for their time, with an average completion time of 16.17 minutes ( $S D=8.17$ minutes; range $=5.25-76.45$ minutes). This procedure was approved by the [institutional review board information blinded for peer review] prior to the beginning of data collection, and all scales were used under fair use policies or via explicit permission from their original authors.

\section{Results}

\section{Stage 1 - Exploratory factor analyses}

An exploratory factor analysis (EFA) using the maximum likelihood extraction method was conducted on the draft GLQ, based on responses provided by the first 900 participants in the data file. In this analysis, equamax rotation was used in order to simplify the subsequent factor structure obtained in the analysis.

Initially, no instructions in relation to the number of factors to extract in the EFA were set. Instead, the scree plot was visually inspected and found the point of inflexion to be located at factor six (see Figure 1). The EFA was then re-ran with an explicit instruction to extract five factors. 


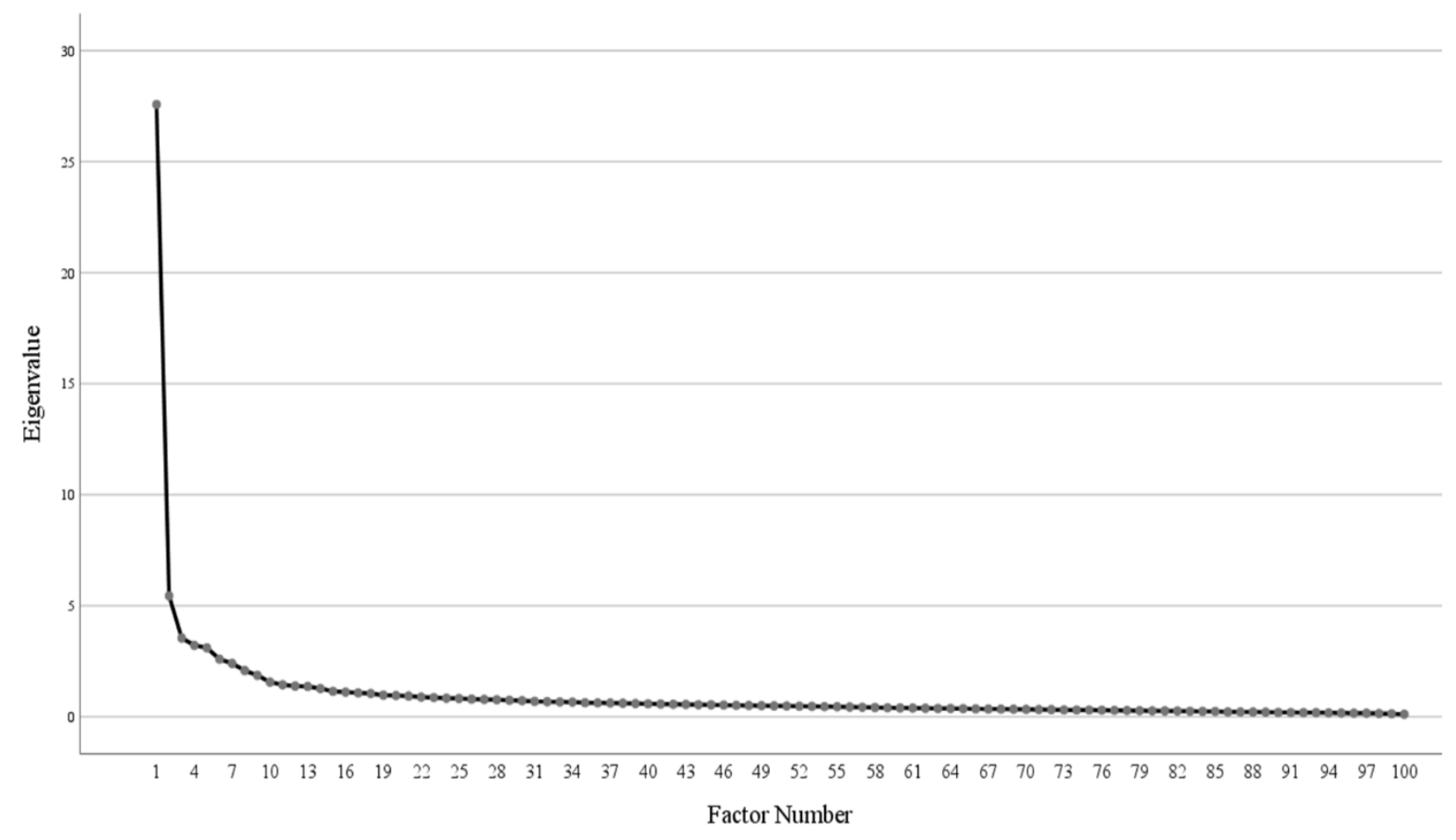

Figure 1. Scree plot for the draft GLQ

The Kaiser-Meyer-Olkin (KMO) measure of sampling adequacy was .96, which is substantially higher than the commonly recommended value of .60 (e.g., Hair, Black, Babin, Anderson, \& Tatham, 2006), and Bartlett's test of sphericity was significant, $\chi^{2}(4950)=$ 53857, $p<.001$. These results confirmed that the data was appropriate for factor analysis. The five factors that were extracted accounted for $39.55 \%$ of the cumulative variance in GLQ scores. For clarity of presentation, Table 2 only presents the significantly-loading items onto each of the five extracted factors (i.e., factor loadings $\geq .50$; Field, 2005). A table demonstrating all item loadings on all 100 draft GLQ items is available for download at https://osf.io/rnxgu/. 
Table 2. Significant item loadings for the draft GLQ

\begin{tabular}{|c|c|c|c|c|c|}
\hline & & & $\mathrm{N}$ & & \\
\hline & 1 & 2 & 3 & 4 & 5 \\
\hline 87. I like my life & .660 & & & & \\
\hline 85. I am content with my current situation & .629 & & & & \\
\hline 59. I am at peace with myself & .626 & & & & \\
\hline 86. I am a happy person & .597 & & & & \\
\hline 10. I've been pretty successful in life & .586 & & & & \\
\hline 55. I can deal with stress effectively & .567 & & & & \\
\hline 50. I have the confidence to make my own way in the world & .553 & & & & \\
\hline 18. I am mentally strong & .548 & & & & \\
\hline 6. I can think of many ways to get the things in life that are important to me & .547 & & & & \\
\hline 90. I feel sad when I think about my life & -.544 & & & & \\
\hline 42. I have a stable working future ahead of me & .542 & & & & \\
\hline 77. I have a purpose in life & .534 & & & & \\
\hline 12. I meet the goals that I set for myself & .523 & & & & \\
\hline 57. I am able to cope when I feel emotionally overwhelmed & .513 & & & & \\
\hline 9. My past experiences have prepared me well for my future & .511 & & & & \\
\hline 38. I am able to develop my career & .501 & & & & \\
\hline
\end{tabular}




\begin{tabular}{|c|c|c|c|c|c|}
\hline & \multicolumn{5}{|c|}{ Factor Number } \\
\hline & 1 & 2 & 3 & 4 & 5 \\
\hline 60. My mental health is poor & -.519 & .541 & & & \\
\hline 32. I wish I could develop more interests & & .532 & & & \\
\hline 34. I find myself being bored quite often & & .530 & & & \\
\hline 88. I often feel down & -.526 & .528 & & & \\
\hline 92. I sometimes feel depressed & -.512 & .526 & & & \\
\hline 3. I feel tired most of the time & & .514 & & & \\
\hline 31. I struggle to find things to do in my free time & & .513 & & & \\
\hline 20. I struggle with my physical health & & .512 & & & \\
\hline 14. I am unhealthy & & .512 & & & \\
\hline 49. I wish I could make more of my own decisions & & .511 & & & \\
\hline 70. I distance myself from others in the community & & & .671 & & \\
\hline 74. I do not feel part of my community & & & .652 & & \\
\hline 71. I feel like I am part of a group & & & -.620 & & \\
\hline 61. I do not have many friends & & & .595 & & \\
\hline 76. I do not like to get involved with my local community & & & .569 & & \\
\hline 68. I have supportive friends & & & -.561 & & \\
\hline
\end{tabular}




\begin{tabular}{lrr}
\hline & Factor Number \\
\cline { 2 - 3 } & 3 & 4 \\
\hline 67. I have a wide social circle & $\mathbf{. . 5 3 5}$ \\
73. I do not share the same values as the rest of my community & $\mathbf{. 5 3 4}$ \\
33. I have lots of interests & $\mathbf{. 6 3 8}$ \\
95. I like to try new things & $\mathbf{. 6 0 9}$ \\
29. I have hobbies & $\mathbf{. 6 0 2}$ \\
30. I regularly participate in different activities & $\mathbf{. 5 2 1}$ \\
36. I am always occupied with an interest or hobby & $\mathbf{. 5 1 6}$ \\
98. I am not creative & $\mathbf{. . 5 0 0}$ \\
84. I am a spiritual person & $\mathbf{. 9 0 9}$ \\
80. I am not spiritual & $\mathbf{- . 8 8 3}$ \\
78. I have trust in a higher power \\
79. I have a strong spiritual bond with the rest of humankind \\
\hline Note. Bolded items are included in the final version of the GLQ A full list of draft GLQ items and their loadings onto each of the five factors.
\end{tabular}

Note. Bolded items are included in the final version of the GLQ. A full list of draft GLQ items and their loadings onto each of the five factors. Negatively-loading items are reverse-scored for their specific factor. 
Factor one ('Inner Peace') contained 19 items that related to contentment with life and mental ability to deal with stress. However, to produce a final scale that is of a practical length for use in applied settings (or in non-applied surveys with limited question space) the decision was made to only include the ten highest-loading items. Example items include 'I am content with my life' and 'I am mentally strong'. Factor two ('Energy and Agency') contained ten items that related to mental stimulation and fatigue. However, three of these items cross-loaded onto factor one (loadings > .50) and were thus removed from the factor. Example items include 'I find myself being bored quite often' and 'I feel tired most of the time' (all items on this factor are phrased negatively, and thus are reverse-scored). Factor three ('Social Connectedness') contained eight items that related to the extent to which participants felt ties to other people, either in terms of close personal friendships or broader ties to local communities. Example items include 'I do not feel part of my local community' (reverse-scored) and 'I have supportive friends'. Factor four ('Varied Leisure Activities') contained six items related to participants' engagement in hobbies and leisure activities. Example items include 'I have lots of interests' and 'I regularly participate in different activities'. Factor five ('Spirituality') contained four items related to participants' deeper bonds with the world and the people within it. Example items include 'I have trust in a higher power' and 'I have a strong spiritual bond with the rest of humankind'.

\section{Stage 2 - Confirmatory factor analyses}

The five-factor structure of the GLQ was interrogated using confirmatory factor analysis in Amos, using data from the remaining 409 participants. The factor solution described above was set as the default model in this analysis.

Each item loaded significantly onto its proposed factor. The default model demonstrated acceptable fit with the data provided by participants, particularly in light of the 
relatively large sample size: $\chi^{2}(500)=1529.30, p<.001$; comparative fit index $(\mathrm{CFI})=.85$; root mean square error of approximation $($ RMSEA $)=.07$.

\section{Stage 3 - Initial scale validation}

Following exploratory and confirmatory factor analyses, data from all participants in the sample $(N=1309)$ were combined in order to provide some initial validation of the GLQ. We then sought to explore the internal consistency and concurrent validity of the GLQ factors using analyses of Cronbach's alpha coefficients, correlations, and a series of linear regressions. Owing to the dimensionality of both the GLQ and the GLM more generally, we did not combined factor scores into a global GLQ score in any of the analyses.

Internal consistency and inter-factor correlations. After the confirmation of the GLQ's factor structure, the internal consistency of each factor was examined using Cronbach's alpha. All factors demonstrated good-to-excellent levels of internal consistency: 'Inner Peace' $\alpha=.93$; 'Energy and Agency' $\alpha=.78$; 'Social Connectedness' $\alpha=.88$; 'Varied Leisure Activities' $\alpha=.81$; 'Spirituality' $\alpha=.84$. Therefore, there is confidence that the final GLQ contains a clear and coherent factor structure, with factors that are internally consistent.

The inter-factor relationships within the GLQ were examined by establishing correlations between the five factors (Table 3). All five factors were significantly associated with each other to a moderate degree, with the exception of Spirituality, which was weakly related to each of the other factors. 
Table 3. Correlations between the GLQ factors

\begin{tabular}{lccccc}
\hline & \multicolumn{5}{c}{ Factor } \\
\cline { 2 - 6 } Factor & 1 & 2 & 3 & 4 & 5 \\
\hline 1. Inner Peace & - & & & \\
2. Energy and Agency & .63 & - & & - & \\
3. Social Connectedness & .62 & .45 & - & .20 & - \\
4. Varied Leisure Activities & .50 & .46 & .48 & .27 & .20 \\
5. Spirituality & .20 & .10 & & \\
\hline
\end{tabular}

$\overline{\text { Note. All coefficients are significant at } p<.001 \text {. Readers are advised to interpret relationships }}$ using absolute effect sizes on account of the large sample size.

Construct validity. In order to establish construct validity, the correlations between each of the GLQ factors and the Psychological Wellbeing Scale, Sense of Community Connectedness Scale, Personal Agency Scale, and the Ten-Item Personality Inventory were examined. It was hypothesized that Inner Peace would be positively related to psychological wellbeing and emotional stability, Social Connectedness to a heightened sense of community connectedness, extraversion, and agreeableness, and Excellence in Play to personal agency and openness to experience.

These expectations were met, even after correcting the level of alpha as a result of multiple correlations being run (amended $p=.001$ ). This indicates that the GLQ possesses good levels of construct validity. Significant correlations between 'Inner Peace' and psychological wellbeing $(r=.79)$ and emotional stability $(r=.67$, 'Social Connectedness' and community connectedness $(r=.59)$, extraversion $(r=.50)$, and agreeableness $(r=.30)$, and 'Varied Leisure Activities' and personal agency $(r=.46)$ and openness to experience ( $r$ $=.63)$ were all observed. Table 4 presents all inter-scale correlations demonstrating construct validity. 
Table 4. Correlations between GLQ factors and other study variables

\begin{tabular}{|c|c|c|c|c|c|c|c|c|}
\hline \multirow[b]{2}{*}{ GLQ Factor } & \multicolumn{8}{|c|}{ Study Scales } \\
\hline & PWB & $\mathrm{SCC}$ & PA & $\mathrm{EV}$ & A & $\mathrm{C}$ & $\mathrm{ES}$ & $\mathrm{O}$ \\
\hline Inner Peace & $.79^{* *}$ & $.46^{* *}$ & $.61^{* *}$ & $.41^{* *}$ & $.25^{* *}$ & $.42^{* *}$ & $.67^{* *}$ & $.24^{* *}$ \\
\hline Energy and Agency & $.64^{* *}$ & $.31^{* *}$ & $.39^{* *}$ & $.24^{* *}$ & $.22^{* *}$ & $.43^{* *}$ & $.53^{* *}$ & $.18^{* *}$ \\
\hline Social Connectedness & $.65^{* *}$ & $.59^{* *}$ & $.40^{* *}$ & $.50^{* *}$ & $.30^{* *}$ & $.27^{* *}$ & $.41^{* *}$ & $.30^{* *}$ \\
\hline Varied Leisure Activities & $.53^{* *}$ & $.34^{* *}$ & $.46^{* *}$ & $.29^{* *}$ & $.18^{* *}$ & $.22^{* *}$ & $.29^{* *}$ & $.63^{* *}$ \\
\hline Spirituality & $.18^{* *}$ & $.22^{* *}$ & $.10^{* *}$ & $.17^{* *}$ & $.23^{* *}$ & $.10^{* *}$ & $.08^{*}$ & $.15^{* *}$ \\
\hline
\end{tabular}

Note. PWB = Psychological Wellbeing Scale. SCC = Sense of Community Connectedness Scale. PA = Personal Agency Scale. EV =

Extraversion. $\mathrm{A}=$ Agreeableness. $\mathrm{C}=$ Conscientiousness. $\mathrm{ES}=$ Emotional Stability. $\mathrm{O}=$ Openness to Experience. Readers are advised to interpret relationships using absolute effect sizes on account of the large sample size.

$* p<.01 * * p<.001$ 
Concurrent validity. In order to establish the concurrent validity of the GLQ, a series of hierarchical multiple regression analysis were ran, directed toward predicting scores on the 'physical aggression', 'verbal aggression', 'anger', and 'hostility' subscales of the Aggression Questionnaire (Buss \& Perry, 1992), as well as the authors' purpose-created crime and delinquency measure. A two-stage hierarchical regression was used in order to establish the added variance explained by the GLQ over-and-above demographic factors associated with aggression, criminality, and delinquency (sex, age, relationship status, level of education, social class, and previous conviction status; Aaltonen, Kivivuori, \& Martikainen, 2011; Piquero, Jennings, Biamond, \& Reingle, 2015). Tables 5-7 present regression coefficients for each predictor in all analyses.

As expected, demographic factors accounted for a small-to-moderate proportion of the variance in all models, with sex (being male), younger age, and having past criminal convictions consistently being significant predictors of self-reported aggression, crime, and delinquency. These generally remained significant predictors upon the addition of the GLQ to our regression models (Tables 5-7). However, adding the GLQ factors significantly increased the proportion of the variance explained in relation to all outcomes (with the exception of self-reported criminal behavior).

Consistently, Social Connectedness was the best GLQ predictor of most outcomes, with this factor being protective (i.e., having a suppressing effect) in relation to indices of aggression, and risk-increasing in relation to self-reported non-criminal delinquent behavior. Following this, Varied Leisure Activities had the opposite effect trends (risk-enhancing on indices of aggression, and protective in relation to delinquency), and Energy and Agency had a consistently protective effect. Inner Peace had a protective effect on emotional indices of aggression (i.e., anger and hostility), but a risk-enhancing effect on verbal aggression. Spirituality generally had weak or null effects on all outcomes, with the exception of a slight 
protective effect on self-reported delinquency. In all, these effects are generally as expected, and support our argument that the GLQ is a valid measure of key constructs that are described within the GLM (Barnao et al., 2010; Loney \& Harkins, 2018; Ward \& Maruna, 2007; Ward \& Stewart, 2003). 
Table 5. Concurrent validity of the GLQ in predicting physical and verbal aggression

\begin{tabular}{|c|c|c|c|c|c|c|c|c|c|c|c|c|}
\hline & \multicolumn{6}{|c|}{ Physical Aggression } & \multicolumn{6}{|c|}{ Verbal Aggression } \\
\hline & \multicolumn{3}{|c|}{ Model 1 - Demographics } & \multicolumn{3}{|c|}{ Model 2 - GLQ } & \multicolumn{3}{|c|}{ Model 1 - Demographics } & \multicolumn{3}{|c|}{ Model 2 - GLQ } \\
\hline & $\bar{B}$ & $\mathrm{SE}$ & $\bar{\beta}$ & $\bar{B}$ & $\mathrm{SE}$ & $\bar{\beta}$ & $B$ & $\mathrm{SE}$ & $\beta$ & $B$ & $\mathrm{SE}$ & $\bar{\beta}$ \\
\hline Sex & .30 & .04 & $.19^{* * * *}$ & .29 & .04 & $.18^{* * * *}$ & .26 & .05 & $.13^{* * * *}$ & .23 & .05 & $.12^{* * *}$ \\
\hline Age & -.01 & .00 & $-.15^{* * *}$ & -.01 & .00 & $-.14^{* * *}$ & -.01 & .00 & $-.09^{* *}$ & -.00 & .00 & $-.05^{\dagger}$ \\
\hline In a Relationship & -.01 & .05 & -.00 & .03 & .05 & .02 & -.02 & .06 & -.01 & -.01 & .06 & -.01 \\
\hline Education & -.10 & .02 & $-.13^{* * *}$ & -.10 & .02 & $-.13^{* * *}$ & -.03 & .03 & -.03 & -.04 & .03 & -.04 \\
\hline Social Class & -.04 & .03 & -.04 & .01 & .03 & .01 & -.03 & .04 & -.02 & .01 & .04 & .00 \\
\hline Ever Convicted & .40 & .11 & $.10^{* * * *}$ & .43 & .11 & $.10^{* * * *}$ & .26 & .14 & .05 & .23 & .14 & $.05^{\dagger}$ \\
\hline GLQ - Inner Peace & & & & .00 & .00 & .00 & & & & .01 & .00 & $.10^{*}$ \\
\hline GLQ - Energy and Agency & & & & -.01 & .01 & $-.09^{*}$ & & & & -.03 & .01 & $-.21^{* * * *}$ \\
\hline GLQ - Social Connectedness & & & & -.01 & .00 & $-.14^{* * *}$ & & & & -.01 & .01 & $-.11^{* *}$ \\
\hline GLQ - Varied Leisure & & & & .00 & .01 & .03 & & & & .03 & .01 & $.15^{* * * *}$ \\
\hline \multicolumn{13}{|l|}{ Activities } \\
\hline GLQ - Spirituality & & & & .00 & .01 & .02 & & & & -.01 & .01 & $-.06^{\dagger}$ \\
\hline Model statistics & \multicolumn{3}{|c|}{$F(6,1289)=21.59, p<.001$} & \multicolumn{3}{|c|}{$F(11,1284)=16.14, p<.001$} & \multicolumn{3}{|c|}{$F(6,1290)=6.87, p<.001$} & \multicolumn{3}{|c|}{$F(11,1285)=8.84, p<.001$} \\
\hline$R^{2}$ & \multicolumn{3}{|c|}{.091} & \multicolumn{3}{|c|}{.121} & \multicolumn{3}{|c|}{.031} & \multicolumn{3}{|c|}{.070} \\
\hline$F$ for $R^{2}$ change & \multicolumn{3}{|c|}{$21.59^{* * *}$} & \multicolumn{3}{|c|}{$8.82^{* * *}$} & \multicolumn{3}{|c|}{$6.87^{* * * *}$} & \multicolumn{3}{|c|}{$10.90^{* * * *}$} \\
\hline
\end{tabular}


Table 6. Concurrent validity of the GLQ in predicting anger and hostility

\begin{tabular}{|c|c|c|c|c|c|c|c|c|c|c|c|c|}
\hline & \multicolumn{6}{|c|}{ Anger } & \multicolumn{6}{|c|}{ Hostility } \\
\hline & \multicolumn{3}{|c|}{ Model 1 - Demographics } & \multicolumn{3}{|c|}{ Model 2 - GLQ } & \multicolumn{3}{|c|}{ Model 1 - Demographics } & \multicolumn{3}{|c|}{ Model 2 - GLQ } \\
\hline & $B$ & $\mathrm{SE}$ & $\beta$ & $B$ & $\mathrm{SE}$ & $\beta$ & $B$ & $\mathrm{SE}$ & $\beta$ & $B$ & $\mathrm{SE}$ & $\beta$ \\
\hline Sex & -.12 & .05 & $-.07^{*}$ & -.11 & .05 & $-.06^{*}$ & -.06 & .06 & -.03 & -.07 & .05 & -.04 \\
\hline Age & -.01 & .00 & $-.10^{* * * *}$ & -.01 & .00 & $-.07^{* *}$ & -.01 & .00 & $-.13^{* * *}$ & -.01 & .00 & $-.07^{* *}$ \\
\hline In a Relationship & .06 & .06 & .03 & .17 & .05 & $.08^{* *}$ & -.21 & .06 & $-.09^{* *}$ & -.02 & .05 & -.01 \\
\hline Education & -.05 & .03 & $-.05^{\dagger}$ & -.04 & .02 & -.04 & .00 & .03 & .00 & .02 & .02 & .02 \\
\hline Social Class & -.08 & .04 & $-.07^{*}$ & .03 & .04 & .02 & -.22 & .04 & $-.16^{* * *}$ & -.01 & .03 & -.01 \\
\hline Ever Convicted & .16 & .13 & .03 & .20 & .13 & .04 & -.02 & .15 & -.00 & .06 & .12 & .01 \\
\hline GLQ - Inner Peace & & & & -.02 & .00 & $-.17^{* * *}$ & & & & -.03 & .00 & $-.24^{* * *}$ \\
\hline GLQ - Energy and Agency & & & & -.03 & .01 & $-.20^{* * *}$ & & & & -.05 & .01 & $-.31^{* * *}$ \\
\hline GLQ - Social Connectedness & & & & -.01 & .00 & $-.09^{*}$ & & & & -.03 & .00 & $-.20^{* * *}$ \\
\hline GLQ - Varied Leisure & & & & .01 & .01 & .05 & & & & .01 & .01 & $.05^{*}$ \\
\hline \multicolumn{13}{|l|}{ Activities } \\
\hline GLQ - Spirituality & & & & .01 & .01 & .02 & & & & .00 & .01 & .00 \\
\hline Model statistics & \multicolumn{3}{|c|}{$F(6,1290)=5.85, p<.001$} & \multicolumn{3}{|c|}{$F(11,1285)=19.29, p<.001$} & \multicolumn{3}{|c|}{$F(6,1289)=13.39, p<.001$} & \multicolumn{3}{|c|}{$F(11,1284)=73.40, p<.001$} \\
\hline$R^{2}$ & \multicolumn{3}{|c|}{.026} & \multicolumn{3}{|c|}{.142} & \multicolumn{3}{|c|}{.059} & \multicolumn{3}{|c|}{.386} \\
\hline$F$ for $R^{2}$ change & \multicolumn{3}{|c|}{$5.85^{* * *}$} & \multicolumn{3}{|c|}{$34.52^{* * *}$} & \multicolumn{3}{|c|}{$13.39^{* * *}$} & \multicolumn{3}{|c|}{$136.94^{* * *}$} \\
\hline
\end{tabular}


Table 7. Concurrent validity of the GLQ in predicting self-reported criminal behavior and delinquency

\begin{tabular}{|c|c|c|c|c|c|c|c|c|c|c|c|c|}
\hline & \multicolumn{6}{|c|}{ Criminal Behavior } & \multicolumn{6}{|c|}{ Delinquency } \\
\hline & \multicolumn{3}{|c|}{ Model 1 - Demographics } & \multicolumn{3}{|c|}{ Model 2 - GLQ } & \multicolumn{3}{|c|}{ Model 1 - Demographics } & \multicolumn{3}{|c|}{ Model 2 - GLQ } \\
\hline & $B$ & SE & $\beta$ & $B$ & $\mathrm{SE}$ & $\beta$ & $B$ & $\mathrm{SE}$ & $\beta$ & $B$ & $\mathrm{SE}$ & $\beta$ \\
\hline Sex & .03 & .01 & $.07^{* *}$ & .03 & .01 & $.08^{* *}$ & .12 & .03 & $.11^{* * * *}$ & .11 & .03 & $.10^{* * *}$ \\
\hline Age & -.00 & .00 & $-.14^{* * *}$ & -.00 & .00 & $-.14^{* * *}$ & -.01 & .00 & $-.13^{* * * *}$ & -.00 & .00 & $-.10^{* * *}$ \\
\hline In a Relationship & -.01 & .01 & -.02 & -.01 & .01 & -.02 & .02 & .03 & .01 & .01 & .03 & .01 \\
\hline Education & -.01 & .01 & -.02 & -.01 & .01 & -.02 & -.00 & .02 & -.01 & .00 & .02 & .00 \\
\hline Social Class & -.01 & .01 & -.05 & -.01 & .01 & -.03 & .03 & .02 & .04 & .04 & .02 & $.05^{\dagger}$ \\
\hline Ever Convicted & .19 & .03 & $.16^{* * *}$ & .19 & .03 & $.16^{* * *}$ & .29 & .08 & $.10^{* * * *}$ & .27 & .08 & $.09^{* *}$ \\
\hline GLQ - Inner Peace & & & & .00 & .00 & -.02 & & & & .00 & .00 & .03 \\
\hline GLQ - Energy and Agency & & & & -.00 & .00 & -.06 & & & & -.01 & .00 & $-.08^{*}$ \\
\hline GLQ - Social Connectedness & & & & .00 & .00 & .01 & & & & .00 & .00 & $.06^{\dagger}$ \\
\hline GLQ - Varied Leisure & & & & -.00 & .00 & -.03 & & & & -.01 & .00 & $-.11^{* *}$ \\
\hline \multicolumn{13}{|l|}{ Activities } \\
\hline GLQ - Spirituality & & & & .00 & .00 & -.00 & & & & -.01 & .00 & $-.09^{* *}$ \\
\hline Model statistics & \multicolumn{3}{|c|}{$F(6,1292)=13.68, p<.001$} & \multicolumn{3}{|c|}{$F(11,1298)=8.28, p<.001$} & \multicolumn{3}{|c|}{$F(6,1292)=8.78, p<.001$} & \multicolumn{3}{|c|}{$F(11,1298)=7.70, p<.001$} \\
\hline$R^{2}$ & \multicolumn{3}{|c|}{.060} & \multicolumn{3}{|c|}{.066} & \multicolumn{3}{|c|}{.039} & \multicolumn{3}{|c|}{.062} \\
\hline$F$ for $R^{2}$ change & \multicolumn{3}{|c|}{$13.68^{* * *}$} & \multicolumn{3}{|c|}{1.76} & \multicolumn{3}{|c|}{$8.78^{* * *}$} & \multicolumn{3}{|c|}{$6.19^{* * * *}$} \\
\hline
\end{tabular}




\section{Discussion}

This paper has presented the development and initial validation of a psychometric measure of the various primary human goods that are conceptually described within the GLM (Ward \& Brown, 2004; Ward et al., 2007; Ward \& Stewart, 2003). In doing so, to our knowledge this is the first attempt to comprehensively test whether: (1) the GLM is comprised of distinct primary human goods, (2) whether these primary human goods are classifiable in the ways described by other authors (e.g., Purvis, 2011; Ward et al., 2007), and

(3) whether the lack of achievement of such primary human goods was associated with selfreported aggression, criminality, and delinquency.

While we did find evidence of dimensionality within the GLM framework, the structure of this was different to how previous conceptual work has described (e.g., Purvis et al., 2011; Ward et al., 2007). That is, rather than finding eleven primary human goods, we found just five factors underpinning the GLQ that we developed, with this five-factor structure being confirmed using an independent sample. These five factors were labelled 'Inner Peace' (the experience of mental wellbeing), 'Energy and Agency' (the experience of hedonic happiness and general interest in life), 'Social Connectedness' (a sense of connection to other people), 'Varied Leisure Activities' (the ability to engage in a broad range of social activities), and 'Spirituality' (a sense of connection to a higher power, or humankind in a general sense). These data suggest that while the GLM offers a theoretically attractive division of 11 primary human goods, these do not emerge quantitatively from a systematic analysis within a large community sample. We do not believe that this has any grave implications for the validity of the philosophical underpinnings of the GLM. That is, the use of positive psychological approaches still has great potential for improving outcomes in forensic contexts (e.g., through improving individuals' levels of wellbeing, improving treatment adherence, reducing dropout rates, and reducing recidivism; Ware \& Bright, 2008) in a similar way to how positive 
approaches are successful in other areas of applied psychology (see Wood \& Tarrier, 2010). Furthermore, they provide a powerful alternative to the traditionally risk-based approach to assessing the likelihood of an individual (re) offending with an emphasis on individual agency and ability to change within the context of an occupational discourse that often is void of such agency (Baumgartner, 2014; Ward \& Maruna, 2007).

There were clear trends in our data about how these clusters of primary human goods were predictive of key outcome variables related to aggression, but less clear associations with self-reported criminal and delinquent behavior. Looking first at aggression, there were expected suppressing effects of Energy and Agency and Social Connectedness on both physical and verbal aggression. Perhaps somewhat counter-intuitively we found positive associations between both Inner Peace and Varied Leisure Activities and verbal aggression. However, these associations may suggest some cathartic effect of verbal aggression in particular contexts (e.g., sporting pursuits) when those involved in such activities are seen as part of a collective community or group. Further, we found that Inner Peace, Energy and Agency, and Social Connectedness were all predictive of lower levels of interpersonal hostility, which may act as a precursor for conflict and associated acts of physical aggression (Borders, Earleywine, \& Jajodia, 2010). This may be particularly important in forensic contexts, with relational goods being associated with fostering personal agency and promoting desistance from crime (Weaver \& McNeil, 2015).

Our lack of significant effects in the model predicting criminal behavior could be related to the low level of self-reported criminality within the sample. As such, there was very little variance in the outcome measure to explain to begin with. We did find more variance explained by the GLQ when examining non-criminal delinquency (e.g., the taking of legal highs, binge drinking, and cheating to get ahead at work). In this model, Energy and Agency, Varied Leisure Activities, and Spirituality all significantly predicted lower levels of 
delinquency. These data suggest that low-level delinquency may be associated with a lack of other activities that provide meaning, purpose, or happiness in life. As such, these may be important domains that require attention within forensic contexts in order to decrease individuals' propensities to engage in criminal or delinquent behavior.

\section{The GLQ and its links to existing literature}

The factors of the GLQ appear to map onto empirically supported protective factors for the reduction of criminal behavior. The factor of 'social connectedness' overlaps with four key protective factors 'stable relationships', 'closeness to others', 'constructive support network' and 'emotional support' (see de Vries Robbé et al., 2015; Ullrich \& Coid, 2011). Ullrich \& Coid (2011) found that significant protective factors for violent offenses centred around positive intact and close interpersonal relationships involving positive support and engagement in activities with family or peers. The factor 'Energy and Agency' links with a sense of control in one's life. Farmer, Beech, and Ward (2011) compared the narratives of potentially desisting men with sexual convictions with those considered still potentially active in their offending. They found that desisters had a stronger sense of personal agency, stronger internal locus of control, and described treatment as a turning point. The factor 'Varied Leisure Activities' links with 'Social Connectedness' in that in essence it is relational. For example, belonging to a group, having a place within a social network and having constructive use of leisure time have been found to be protective for men with violent and sexual convictions (Ullrich \& Coid, 2011; Serin, Chadwick, \& Lloyd, 2016). Spirituality is another important protective factor. On an individual level, religiosity is associated with enhanced mood (Hicks \& King, 2008) and an increased ability to cope with stressful events (Gall, Malette \& Guirguis-Younger, 2011). It has also been found to allow for cognitive transformation and positive identity change in men with sexual convictions (see Blagden, 
Winder, \& Lievesley, 2020). Finally, 'Inner Peace' or the experience of positive mental wellbeing related to rehabilitation and treatment gains in men with sexual convictions (Willis \& Ward, 2013).

Importantly, the links to protective factors are aligned with the GLM and more generally with human flourishing (i.e., helping people develop meaningful constructive offense-free lives; Ward \& Stewart, 2003). While research demonstrates that such factors yield incremental predictive validity, that it relevant to case formulation and understanding pathways to desistance, this is not common practice (Serin et al., 2016). This emphasises the importance and utility of a measure such as the GLQ in that it can measure factors conceptually aligned to protective and desistance factors.

\section{Future directions and further validation of the GLQ}

While this paper highlights the potential utility of the GLQ as an assessment of GLMrelated primary goods, there are a number of further studies that could provide further evidence of its place as a validated measure in this area of practice and scholarship. For example, the analyses contained within this paper stem from data collected from community members. As such, although we observed relatively high levels of problematic aggression in our sample, it contained a low base rate of both self-reported criminal behavior and delinquency. While some reviewers of the present work may consider this to be a key limitation of our study, we consider it a necessary first step in quantifying the primary human goods. That is, consistent with previous theorizing (Ward \& Birgden, 2007) and prior attempts to standardize the measurement of the GLM framework (Loney \& Harkins, 2018), we view the primary human goods to be universal constructs, meaning that all people (offending and non-offending) are striving to achieve them. In establishing the GLQ using a normative (i.e., non-offending) sample we have been able to show how these primary human 
goods are organized in a normative sample. One vital next step would be to confirm the GLQ factor structure within a prison-based population, possibly with a non-incarcerated control group, and establish whether scores on the GLQ can discriminate between these groups. Conducting these analyses would provide further evidence of the psychometric strength of the measure itself, but also about its validity as a measure of the primary goods comprising the GLM. Of course, it is possible that the GLQ may have a different factor structure in an offending sample. This in itself raises an interesting theoretical question, in that we may begin to question the universality of primary human goods, should this be the case. That notwithstanding, we observed a relatively high level of aggression within our sample, which may be suggestive of some transferability of our findings into the forensic domain at this early stage of scale validation. Nonetheless, extension of this work into the offending domain is an essential next step.

In order to enhance the utility of the GLQ in applied settings and overcome some of the limitations of self-report completion methods, it would be useful to explore how self-reported scores for each of the primary human good clusters correlates with ratings provided by others. For example, is there a relationship between the scores provided by respondents themselves and by those known to them (e.g., family members for those within the community, or professionals providing correctional programs for those who are incarcerated). By exploring these relationships, it may be possible to use the GLQ as an instrument for formulating potential areas for improvement or focus for individuals who are in correctional or other psychological services. Moreover, qualitative studies might look to explore how individuals look to access primary human goods in an anti-social manner, with the aim being to identify the clusters of primary human goods (as set out in the GLQ) that are of importance to those individuals. This work may be conducted alongside other more established approaches to studying the achievement of primary human goods (see Yates et al., 2009) in 
order to provide evidence of the GLQ's convergent validity. Identifying important clusters of primary human goods in this way will help to improve the responsivity of correctional treatments, and augment the use of the GLQ (as thus the GLM framework) with established risk-need-responsivity principles of rehabilitation for people with criminal convictions (Andrews et al., 2011). Subsequent iterations of the GLQ may also look to include additional questions relating to the relative importance of each primary human good cluster to individual service users in order to enhance the responsivity of their treatment (see Yates et al., 2009).

The predictive validity of the GLQ in relation to in-prison behavior or re-offending risk should be explored. This would ideally make use of the GLQ in a prospective, rather than concurrent or retrospective, manner. If responses are seen to be associated with such outcomes (i.e., if specific primary human good clusters are associated with more positive outcomes in the form of enhanced treatment program engagement, fewer adjudications, or reduced recidivism upon release), then ways to increase scores in these domains should be explored and embedded into treatment protocols. This could go some way to addressing some of the concerns about the lack of evidence base used when incorporating principles related to the GLM into existing correctional programs (Andrews et al., 2011; Looman \& Albracen, 2013).

Away from specific forensic contexts, it may be a fruitful area of investigation to examine whether offending proclivity in 'at-risk' populations (e.g., non-criminally delinquent youths, individuals with atypical sexual interests, or those with drug / alcohol misuse issues) is moderated by scores on particular GLQ domains. This is an exciting possibility as it means that principles related to the GLM could be embedded into offending prevention programs in a bid to reduce criminality before it occurs, as well in the reduction of recidivism among groups with pre-existing offenses. 


\section{Conclusions}

In this paper, we have addressed a substantial gap in the current evidence based related to the GLM by systematically developing and validating a measure of primary human goods within the general population. In doing so, we cast doubt over the conceptually-attractive division of primary human goods, and instead offer a five-factor conceptualization of the GLM on the basis of our empirical data. While this paper represents an initial starting point to studying the GLM in a more empirical manner than has previously been possible, there is still more work to be done to establish the GLQ as a reliable and valid measure in forensic contexts (see above). Nonetheless, the measure shows promise in differentially predicting aggressive behavior and self-reported prior criminality and delinquency. From here, subsequent studies should be designed to explore its utility and consistency in applied contexts in order to explore the practical relevance of the GLM when tested under empirical conditions. 


\section{References}

Aaltonen, M., Kivivuori, J., \& Martikainen, P. (2011). Social determinants of crime in a welfare state: Do they still matter? Acta Sociologica, 54, 161-181. doi: $10.1177 / 0001699311402228$.

Akerman, G. (2008). The development of a fantasy modification programme in a prisonbased therapeutic community. International Journal of Therapeutic Communities, 29, 180188.

Akerman, G. (2019). Communal living as the agent of change. In D. L. L. Polaschek, A. Day, \& C. R. Hollin (Eds.), The Wiley handbook of correctional psychology (pp. 590-602). Chichester: John Wiley \& Sons.

Andrews, D. A., \& Bonta, J. (1994). The psychology of criminal conduct. Lexington, KY: Anderson Publishing Co.

Andrews, D. A., Bonta, J., \& Wormith, J. S. (2006). The recent past and near future of risk and/or need assessment. Crime \& Delinquency, 52, 7-27. doi: $10.1177 / 0011128705281756$.

Andrews, D. A., Bonta, J., \& Wormith, S. (2011). The risk-need-responsivity (RNR) model: Does adding the good lives model contribute to effective crime prevention? Criminal Justice and Behavior, 38, 735-755. doi: 10.1177/0093854811406356.

Archer, J., \& Webb, I. A. (2006). The relation between scores on the Buss-Perry aggression questionnaire and aggressive acts, impulsiveness, competitiveness, dominance, and sexual jealousy. Aggressive Behavior, 32, 464-473. doi: 10.1002/ab.20146.

Barnao, M., Robertson, P., \& Ward, T. (2010). Good lives model applied to a forensic population. Psychiatry, Psychology and Law, 17, 202-217. doi:

$10.1080 / 13218710903421274$. 
Baumgartner, E. C. G. (2014) Boys will be boys, or will they? A study of youth offending team practitioners' constructions of masculinity of the young men with whom they work. Unpublished doctoral thesis. Durham University, UK.

Blagden, N., Winder, B., \& Lievesley, R. (2020). 'The resurrection after the old has gone and the new has come': Understanding narratives of forgiveness, redemption and resurrection in Christian individuals serving time in custody for a sexual offence. Psychology, Crime \& Law, 26, 34-52. doi: 10.1080/1068316X.2019.1634194.

Borders, A., Earleywine, M., \& Jajodia, A. (2010). Could mindfulness decrease anger, hostility, and aggression by decreasing rumination? Aggressive Behavior, 36, 28-44. doi: 10.1002/ab.20327.

Brookes, M. (2010). Putting Principles into Practice: The Therapeutic Community Regime at HMP Grendon and its relationship with the 'Good Lives' model. In E. Sullivan \& R. Shuker (Eds.), Grendon and the emergence of forensic therapeutic communities: Developments in research and practice (pp. 99-113). Chichester: Wiley.

Buss, A. H., \& Perry, M. (1992). The aggression questionnaire. Journal of Personality and Social Psychology, 63, 452-459. doi: 10.1037/0022-3514.63.3.452.

Chen, P., Voisin, D. R., \& Jacobson, K. C. (2016). Community violence exposure and adolescent delinquency: Examining the spectrum of promotive factors. Youth \& Society, 48, 33-57. doi: 10.1177/0044118X13475827.

Chung, J. E., Song, G., Kim, K., Yee, J., Kim, J. H., Lee, K. E., \& Gwak, H. S. (2019). Association between anxiety and aggression in adolescents: A cross-sectional study. $B M C$ Paediatrics, 19, e115. doi: 10.1186/s12887-019-1479-6.

Costello, A. B., \& Osborne, J. W. (2005). Best practices in exploratory factor analysis: Four recommendations for getting the most from your analysis. Practical Assessment, Research \& Evaluation, 10, 1-9. 
de Schutter, M. A. M., Kramer, H. J. M., T., Franken, E. J. F., Lodewijkx, H. F. M., \& Kleinepier, T. (2016). The influence of dysfunctional impulsivity and alexithymia on aggressive behavior of psychiatric patients. Psychiatry Research, 243, 128-134. doi: 10.1016/j.psychres.2016.06.023.

De Vries Robbé, M., Mann, R. E., Maruna, S., \& Thornton, D. (2015). An exploration of protective factors supporting desistance from sexual offending. Sexual Abuse, 27, 16-33. doi: $10.1177 / 1079063214547582$.

Elliott, D. S., Huizinga, D., \& Ageton, S. S. (1985). Explaining delinquency and drug use. Beverly Hills, CA: Sage.

Ferracuti, S. (1996). Cesare Lombroso (1835-1907). Journal of Forensic Psychiatry, 7, 130149. doi: $10.1080 / 09585189608409921$.

Flanagan, C. A., Cumsille, P., Gill, S., \& Gallay, L. S. (2007). School and community climates and civic commitments: Patterns for ethnic minority and majority students. Journal of Educational Psychology, 99, 421-431. doi: 10.1037/0022-0663.99.2.421.

Gill, T. L., Malette, J., \& Guirguis-Younger, M. (2011). Spirituality and religiousness: A diversity of definitions. Journal of Spirituality in Mental Health, 13, 158-181. doi: $10.1080 / 19349637.2011 .593404$.

Gosling, S. D., Rentfrow, P. J., \& Swann, W. B. (2003). A very brief measure of the Big-Five personality domains. Journal of Research in Personality, 37, 504-528. doi: 10.1016/S0092-6566(03)00046-1.

Hair, J. F., Black, W. C., Babin, B. J., Anderson, R. E., \& Tatham, R. L. (2006). Multivariate data analysis. Upper Saddle River, NJ: Pearson University Press.

Hanson, R. K., Harris, J. R., Helmus, L., Thornton, D. (2014). High-risk sex offenders may not be high risk forever. Journal of Interpersonal Violence, 29, 2792-2813. doi: $10.1177 / 0886260514526062$. 
Harkins, L., Flak, V. E., Beech, A. R., \& Woodhams, J. (2012). Evaluation of a communitybased sex offender treatment program using a good lives model approach. Sexual Abuse, 24, 519-543. doi: 10.1177/1079063211429469.

Helgeson, V. S., \& Palladino, D. K. (2012). Agentic and communal traits and health: Adolescents with and without diabetes. Psychology and Social Psychology Bulletin, 38, 415-428. doi: 10.1177/0146167211427149.

Hicks, J. A., \& King, L. A. (2008). Religious commitment and positive mood as information about meaning in life. Journal of Research in Personality, 42, 43-57. doi: 10.1016/j.jrp.2007.04.003.

Home Office. (1995). Dealing with dangerous people: The probation service and public protection. London: Home Office.

Laws, D. R., \& Ward, T. (2011). Desistance from sex offending: Alternatives to throwing away the keys. New York, NY, US: The Guilford Press.

LeBel, T. P., Burnett, R., Maruna, S., \& Bushway, S. (2008). The chicken and egg of subjective and social factors in desistance from crime. European Journal of Criminology, 5, 131-159. doi: 10.1177/1477370807087640.

Loney, D. M., \& Harkins, L. (2018). Examining the good lives model and antisocial behavior. Psychology, Crime \& Law, 24, 383-51. doi: 10.1080/1068316X.2017.1371304.

Looman, J., \& Albracen, J. (2013). The risk need responsivity model of offender rehabilitation: Is there really a need for a paradigm shift? International Journal of Behavioral Consultation and Therapy, 8, 30-36. doi: 10.1037/h0100980.

Mann, R. E. (2004). Innovations in sex offender treatment. Journal of Sexual Aggression, 10, 141-152. doi: 10.1080/1355260042000261751. 
Marshall, W. L., Marshall, L. E., Serran, G. A., \& O'Brien, M. D. (2011). Rehabilitating sexual offenders: A strength-based approach. Washington: DC: American Psychological Association.

Maruna, S. (2001). Making good. Washington, DC: American Psychological Association.

Maslow, A. H. (1948). "Higher" and "lower" needs. The Journal of Psychology: Interdisciplinary and Applied, 25, 433-436. doi: 10.1080/00223980.1948.9917386.

McMurran, M., \& Ward, T. (2004). Motivating offenders to change in therapy: An organizing framework. Legal and Criminological Psychology, 9, 295-311. doi: $10.1348 / 1355325041719365$.

Mundfrom, D. J., Shaw, D. G., \& Ke, T. L. (2005). Minimum sample size recommendations for conducting factor analyses. International Journal of Testing, 5, 159-168. doi: 10.1207/s15327574ijt0502_4.

Musumeci, E. (2013). New natural born killers? The legacy of Lombroso in neuroscience and law. In P. Knepper and P. J. Ystehede (Eds.), The Cesare Lombroso handbook (pp. 143158). Oxon: Routledge.

Myers, N. D., Ahn, S., \& Jin, Y. (2011). Sample size and power estimates for a confirmatory factor analytic model in exercise and sport: A Monte Carlo approach. Research Quarterly for Exercise and Sport, 82, 412-423. doi: 10.1080/02701367.2011.10599773.

Netto, N. R., Carter, J. M., \& Bonell, C. (2014). A systematic review of interventions that adopt the "good lives" approach to offender rehabilitation. Journal of Offender Rehabilitation, 53, 403-432. doi: 10.1080/10509674.2014.931746.

Phoenix, J. (2009). Beyond risk assessment: The return of repressive welfarism? In M. Barry \& F. McNeill (Eds.), Youth offending and youth justice. London: Jessica Kingsley Publisher. 
Piquero, A. R., Jennings, W. G., Diamond, B., \& Reingle, J. M. (2015). A systematic review of age, sex, ethnicity, and race as predictors of violent recidivism. International Journal of Offender Therapy and Comparative Criminology, 59, 5-26. doi: 10.1177/0306624X13514733.

Prins, H. (1996). Risk assessment and management in criminal justice and psychiatry. Journal of Forensic Psychiatry, 7, 42-62. doi: 10.1080/09585189608409916.

Purvis, M., Ward, T., \& Willis, G. (2011). The good lives model in practice: Offence pathways and case management. European Journal of Probation, 3, 4-28. doi: $10.1177 / 206622031100300202$.

Serin, R. C., Chadwick, N., \& Lloyd, C. D. (2016). Dynamic risk and protective factors. Psychology, Crime \& Law, 22, 151-170. doi: 10.1080/1068316X.2015.1112013.

Snyder, C. R., Harris, C., Anderson, J. R., Holleran, S. A., Irving, L. M., Sigmon, S. T., ... \& Harney, P. (1991). The will and the ways: Development and validation of an individualdifferences measure of hope. Journal of Personality and Social Psychology, 60, 570-585. doi: 10.1037/0022-3514.60.4.570.

Tremblay, P. F., \& Ewart, L. A. (2005). The Buss and Perry aggression questionnaire and its relations to values, the big five, provoking hypothetical situations, alcohol consumption patterns, and alcohol expectancies. Personality and Individual Differences, 38, 337-346. doi: 10.1016/j.paid.2004.04.012.

Ullrich, S., \& Coid, J. (2011). Protective factors for violence among released prisoners Effects over time and interactions with static risk. Journal of Consulting and Clinical Psychology, 79, 381-390. doi: 10.1037/a0023613.

Villar, F., Triadó, C., Celdrán, M., \& Solé, C. (2010). Measuring well-being among Spanish older adults: Development of simplified version of Ryff's Scale of Psychological Well- 
being. Psychological Reports, 107, 265-280. doi: 10.2466/02.07.08.10.21.PR0.107.4.265280.

Ward, T., \& Birgden, A. (2007). Human rights and correctional clinical practice. Aggression and Violent Behavior, 12, 628-643. Doi: 10.1016/j.avb.2007.05.001.

Ward, T., \& Fortune, C.-A. (2013). The good lives model: Aligning risk reduction with promoting offenders' personal goals. European Journal of Probation, 5, 29-46. doi: $10.1177 / 206622031300500203$

Ward, T., \& Gannon, T. A. (2006). Rehabilitation, etiology, and self-regulation: The comprehensive good lives model of treatment for sexual offenders. Aggression and Violent Behavior, 11, 77-94. doi: 10.1016/j.avb.2005.06.001.

Ward, T., Gannon, T. \& Mann, R. (2007). The good lives model of offender rehabilitation: Clinical implications. Aggression and Violent Behavior, 12, 87-107. doi: 10.1016/j.avb.2006.03.004.

Ward, T., \& Maruna, S. (2007). Rehabilitation. Oxon: Routledge.

Ward, T., \& Marshall, W. L. (2004). Good lives, aetiology and the rehabilitation of sex offenders: A bridging theory. Journal of Sexual Aggression, 10, 153-169. doi: $10.1080 / 13552600412331290102$.

Ward, T., \& Stewart, C. A. (2003). The treatment of sex offenders: Risk management and good lives. Professional Psychology: Research and Practice, 34, 353-360. doi: 10.1037/0735-7028.34.4.353.

Ware, J., \& Bright, D. A. (2008). Evolution of a treatment programme for sex offenders: Changes to the NSW Custody-Based Intensive Treatment (CUBIT). Psychiatry, Psychology and Law, 15, 340-349. doi: 10.1080/13218710802014543.

Weaver, B., \& McNeill, F. (2015). Lifelines: Desistance, social relations, and reciprocity. Criminal Justice and Behavior, 42, 95-107. 
Willis, G. M., Yates, P. M., Gannon, T. A., \& Ward, T. (2013). How to integrate the Good Lives Model into treatment programs for sexual offending: An introduction and overview. Sexual Abuse, 25, 123-142. doi: 10.1177/1079063212452618.

Willis, G. M., \& Ward, T. (2013). The good lives model: Does it work? Preliminary evidence. In L. A Craig, L. Dixon, \& T. A. Gannon (Eds.), What works in offender rehabilitation: An evidence-based approach to assessment and treatment (pp. 305-317). Chichester: John Wiley \& Sons.

Woldgabreal, Y., Day, A., \& Ward, T. (2014). The community-based supervision of offenders from a positive psychology perspective. Aggression and Violent Behavior, 19, 32-41. doi: 10.1016/j.avb.2013.12.001.

Woldgabreal, Y., Day, A., \& Ward, T. (2016). Linking positive psychology to offender supervision outcomes: The mediating role of psychological flexibility, general selfefficacy, optimism, and hope. Criminal Justice and Behavior, 43, 697-721. doi: $10.1177 / 0093854815620816$.

Wood, A. M., \& Tarrier, N. (2010). Positive clinical psychology: A new vision and strategy for integrated research and practice. Clinical Psychology Review, 30, 819-829. doi: 10.1016/j.cpr.2010.06.003.

Yates, P., Kingston, D., \& Ward, T. (2009). The self-regulation model of the offence and reoffence process - Volume 3: A workbook for the assessment and treatment of sexual offenders. Victoria, BC: Pacific Psychological Assessment Corporation.

Yates, P. M., \& Prescott, D. S. (2011). Building a better life: A good lives and self-regulation workbook. Brandon, VT: Safer Society Press.

Zamble, E., \& Quinsey, V. L. (1997). The criminal recidivism process. Cambridge: Cambridge University Press. 


\section{Appendix - The Good Lives Questionnaire}

Please read the statements below and rate how much you agree with them using the scale provided. There are no right or wrong answers, so please be as honest as possible.

(1) Strongly Disagree, (2) Disagree, (3) Somewhat Disagree, (4) Somewhat Agree, (5) Agree, (6) Strongly Agree

\begin{tabular}{|c|c|c|}
\hline Iten & & Factor \\
\hline 1 & I wish I could make more of my own decisions ( $\mathrm{r}$ ) & Energy and Agency \\
\hline 2 & I feel sad when I think about my life (r) & Inner Peace \\
\hline 3 & I can think of many ways to get the things in life that are important to me & Inner Peace \\
\hline 4 & I struggle to find things to do in my free time $(r)$ & Energy and Agency \\
\hline 5 & I distance myself from others in the community (r) & Social Connectedness \\
\hline 6 & I do not like to get involved with my local community (r) & Social Connectedness \\
\hline 7 & I can deal with stress effectively & Inner Peace \\
\hline 8 & I do not have many friends (r) & Social Connectedness \\
\hline 9 & I have a wide social circle & Social Connectedness \\
\hline 10 & I find myself being bored quite often $(r)$ & Energy and Agency \\
\hline 11 & I like my life & Inner Peace \\
\hline 12 & I am not spiritual (r) & Spirituality \\
\hline 13 & I have the confidence to make my own way in the world & Inner Peace \\
\hline 14 & I am mentally strong & Inner Peace \\
\hline 15 & I have supportive friends & Social Connectedness \\
\hline 16 & I am a happy person & Inner Peace \\
\hline 17 & I am always occupied with an interest or hobby & Varied Leisure Activities \\
\hline 18 & I regularly participate in different activities & Varied Leisure Activities \\
\hline 19 & I am content with my current situation & Inner Peace \\
\hline 20 & I have a strong spiritual bond with the rest of humankind & Spirituality \\
\hline 21 & I am not creative (r) & Varied Leisure Activities \\
\hline 22 & I have trust in a higher power & Spirituality \\
\hline 23 & I do not share the same values as the rest of my community (r) & Social Connectedness \\
\hline 24 & I have hobbies & Varied Leisure Activities \\
\hline 25 & I am a spiritual person & Spirituality \\
\hline 26 & I feel tired most of the time (r) & Energy and Agency \\
\hline 27 & I am at peace with myself & Inner Peace \\
\hline 28 & I have lots of interests & Varied Leisure Activities \\
\hline 29 & I wish I could develop more interests ( $r$ ) & Energy and Agency \\
\hline 30 & I like to try new things & Varied Leisure Activities \\
\hline 31 & I am unhealthy (r) & Energy and Agency \\
\hline 32 & I do not feel part of my community (r) & Social Connectedness \\
\hline 33 & I feel like I am part of a group & Social Connectedness \\
\hline 34 & I struggle with my physical health (r) & Energy and Agency \\
\hline 35 & I've been pretty successful in life & Inner Peace \\
\hline
\end{tabular}

(r) indicates that the item is reverse-scored 